\section{International Scientific Journal Theoretical \& Applied Science}

\author{
p-ISSN: 2308-4944 (print) e-ISSN: 2409-0085 (online) \\ Year: $2014 \quad$ Issue: $10 \quad$ Volume: 18
}

Sanobar Narzikulovna Akbarova Candidate of psychological sciences, Tashkent Pediatric Medical institute,

Uzbekistan sanobarakbarova@tashpmi.uz

Albina Nigmatjanovna Sahojko Assistant, Tashkent Pediatric Medical institute, Uzbekistan

SECTION 20. Medicine.

\title{
THE PROBLEMS OF THE STUDYING PSYCHOLOGICAL DERMATOGLYPHICS OF THE SCHIZOPHRENIA PATIENTS
}

Abstract: The article analyzed literary data about connection between dermatoglyphics and schizophrenia. Problems on a way of studying of hereditary-psychological lines of persons sick of a schizophrenia are revealed. Some not studied parties psychological dermatoglyphics are described.

Key words: Medical psychology, mental diseases, character, dermatoglyphics, the person, schizophrenia.

Citation: Akbarova SN, Sahojko AN (2014) THE PROBLEMS OF THE STUDYING PSYCHOLOGICAL DERMATOGLYPHICS OF THE SCHIZOPHRENIA PATIENTS. ISJ Theoretical \& Applied Science 10 (18): 7 10. doi: http://dx.doi.org/10.15863/TAS.2014.10.18.2

\section{УДК 159.9.616.89}

\section{ПРОБЛЕМЫ ИЗУЧЕНИЯ ПСИХОЛОГИЧЕСКОЙ ДЕРМАТОГЛИФИКИ БОЛЬНЫХ ШИЗОФРЕНИЕЙ}

Аннотация: В статье анализируются литературные данные о связи дерматоглифики с шизофренией. Выявлены проблемы на пути изучения наследственных-психологических черт личностей больных иизофренией. Описаны некоторые не изученные стороны психологической дерматоглифики.

Ключевые слова: медицинская психология, психические заболевания, характер, дерматоглифика, личность, иизофрения

Медицинская психология - один из направлений психологии. В некоторых литературах медицинскую психологию отличают от клинической психологии [1, С. 118], но в других они описываются как единая наука с двойственным названием [2, С. 3]. И всё же, не смотря на расхождения мнений, основным содержанием клинической (медицинской) психологии как науки, стоящей на пересечении медицины и психологии, является (по Э.Кречмеру, 1922) психологический анализ природы болезней.

На сегодняшний день изучение психологической картины различных заболеваний осуществляется с помощью наблюдения и проведения у больных психологических тестов. Но к сожалению этот путь не даёт информацию о природе происхождения этой психологической картины, находящийся под влиянием нескольких факторов, таких как наследственность, социальная обусловленность, врождённость (хотя сам болезнь отмечается врачами как эндогенная или экзогенная). В наших предыдущих работах мы предложили включить в этот список ещё один фактор - сам болезнь. Это означает, что характерологические особенности личности больного могут быть подболезненными (появляются только под воздействием болезни), которых можно далее характеризовать как обратимые и необратимые [3]. Изучение психологии больных, таким образом, даёт ясную картину, где можно выделить какие именно наследственно приобретённые черты характера имеют значение в возникновении болезни и наоборот какую психологическую особенность больной приобрел под воздействием болезни. В психиатрии существует термин «преморбидный личность» той или иной болезни, но также необходимо констатировать подболезненность психологических особенностей больного, если они обнаружены. 
Относительно наследственных характерных черт личности, их изучение можно осуществить с помощью метода дерматоглифики, который был предложен нами, сочтённым одним из методов психологических исследований [4].

В научных работах учёных выявлена связь дерматоглифики со многими наследственными заболеваниями, в том числе и тех, которые изучают психиатры. Один из этих заболеваний, является болезнь шизофрении. По литературным данным этот болезнь охватывает 1 \% населения мира (около 50 млн человек) [5, С.79]. По данным Э.Крепелина, прямая наследственная отягощенность у больных шизофренией составляет $33,7 \%$ [5, С.89]. По А.Розенталю генетический фактор шизофрении составляет $89 \%$ $[5$, C.90].

Существует много научных работ посвящённые изучению связи дерматоглифики с болезней шизофрении [6-13]. Также уделено внимание на психологические особенности больных шизофренией [5,6,14,15].

Наша гипотеза гласит, что если наследственная болезнь имеет определенную психологическую картину (личностные характерологические черты пациентов), то эти же черты характера в той или иной степени отражаются в дерматоглифических признаках, которые считаются генетическим маркером этой болезни. Если описать эту взаимосвязь в триаде: углы состоят из болезни, дерматоглифики и психологических свойств. Наша предыдущая работа доказывает эту гипотезу, где показана психологическая-наследственная характеристика больных гипертензией [16]. А также показали наследственные характерные черты личности свойственные больным наркоманией, где мы считаем, что сама болезнь не передаётся генетическим путём [3]. Их можно назвать по Н.П. Бадикову как «психологическая дерматоглифика» той или иной болезни [17].

Таким образом, можно также выявить наследственные характерные черты больных шизофренией, а именно путём сравнительного анализа данных дерматоглифических признаков больных шизофренией и психологических особенностей больных шизофренией опираясь на работы [19-21], проделанные по изучению связи дерматоглифики с психологическими чертами личности.

Но, к сожалению, в литературных данных болезнь шизофрении и связь её с дерматоглификой имеет противоположный характер. Например, по А.А. Зайченко у мужчин паранойяльной шизофренией Саратовской области достоверно чаще встречается узор завитка и двойной петли ( $\mathrm{p}=0,005)$ на пальцах [6]. Исследования Б.А.Абдуллаева, А.А. Даминова в узбекской популяции подтверждают эти данные, но с утверждением, что общий гребневой счет у больных обеих полов значительно уменьшён [9]. Когда как, в иранской популяции по Shakibaei F., Asadollahi G. A., Tabibi A. значимые различия в пальцевых узорах не было выявлено, а гребневой счет у мужчин отмечено больше, чем здоровые мужчины ( $p$ < 0.05) [7]. Увеличение общего гребневого счета отмечается и в работах C.J. van Oel, W.F.Baaré и др. [13]. В других работах у шизофрении отмечается значительная флуктуирующая асимметрия [12,13], но есть работы где это не нашла подтверждения [10]. Увеличение гребневого счета между трирадиусами А и В (ГСАВ) выявлено р <0,05 [11]. Есть данные, где показана увеличение встречаемости узора арка (А) на пальцах больных шизофрении [8]. Такая картина усложняет изучения психологической дерматоглифики больных шизофренией. Существуюее расхождение же можно объяснить тем, что до сих пор в диагностике шизофрении не существуют единого мнения. Например, Ю.А.Антропов утверждает, что в МКБ-10 приведенные симптомы для установления шизофрении (где считается вполне достаточным проявления в течении месяца одного четкого или двух менее четких симптомов, принадлежащих к группе «а-г» или двух симптомов из группы «Д-и») наблюдаются не только при шизофрении, но и при других заболеваниях (травматические, алкогольные, сосудистые психозы, в клинике психозов при энцефалитах, интоксикациях, инфекциях) [5, С.94].

Что касается психологических особенностей этой болезни, в литературе они характеризуются следующим образом. Больным шизофрении свойственно агрессия [6,14], растерянность [14], замкнутость, отчуждённость, утрата интереса к окружающему и к какой либо деятельности $[18$, С. 400]. С детства отмечается робость, застенчивость, склонность к уединению, пассивность, серьёзность, не уверенность в себе [5, С.91], не смелость, трудность установления контакта с окружающим, чувство неполноценности, компенсируемое склонностью к фантазиям, чрезмерное подчиняемость [15, С.7]. Больше четверти $(25,5 \% ; 14$ чел.) преморбидных личностных особенностей паранойяльной шизофрении приходилась на шизоидные черты [14].

Из этих психологических свойств мы можем выделить те, которые имели достоверную связь с дерматоглификой в наших предыдущих работах. Это - агрессия [19], застенчивость (робость) [20], склонность к уединению, серьёзность, способность к фантазиям. Они имеют $\mathrm{p}<0,5$ и $\mathrm{p}<0,1$. И если термин «смелость» можно считать синонимом термина «храбрость», то храбрость тоже отражается в дерматоглифике $\mathrm{p}<0,01$ [20]. 
Следуя закономерности наследственности психологических свойств личности [20,21] эти психологические черты характера имеют наследственную основу.

Но сравнивая дерматоглифические маркеры болезни шизофрении и характерологических черт свойственные этой болезни, мы не нашли сходство ни с одним параметром описанные выше авторами. Например, по А.А. Зайченко преобладающие узоры завитков и двойной петли в ущерб ульнарной петли на пальцах по нашим данным достоверно связаны не серьезностью, то есть они обратно пропорциональны с чертой серьёзностью. Эти расхождения ещё раз показывает многообразие проявления шизофрении, которая должна быть изучено подразделенным образом, добивая однородности симптомов и т.д. Например, наши пилотажные исследования дерматоглифики 10 мужчин больных параноидной шизофренией (из них непрерывно текущей формой 9 больных), а именно в истории болезни, отмеченные как агрессивные, в девяти случаях имели маркер агрессивной дерматоглифики [19]. Также было обнаружено асимметрия в окончаниях главных ладонных линий на этих 9 больных, но на наших исследованиях не полностью изучено связь асимметрических дерматоглифических признаков (из за нехватки репрезентативной группы) и гребневые счета с психологическими особенностями личности.

Из выше изложенных положений формируется вывод, что изучение болезни шизофрении, и её связь с дерматоглификой должно быть осуществлено в группах больных, где выявлена однородность как можно больше параметров изучаемых больных.

Подведя итоги важно подчеркнуть, что эффективность изучения психологической дерматоглифики различных заболеваний зависит от точности классификации, диагностики исследуемой болезни. Что касается болезни шизофрении, для описания психологической дерматоглифики этой болезни нужно исследовать отдельно связь психологических свойств личности с такими дерматоглифическими признаками как общий гребневой счет, гребневой счет между А и В трирадиусов и асимметрия признаков. Также пока не существуют данные о природе происхождения психологического свойства как подчинённость, которая выше было сказано как свойственно к шизофрении. Мы предполагаем, что типы акцентуации также могут иметь достоверную связь с дерматоглификой, которые должны быть отдельно изучены.

\section{References:}

1. Haydarov F, Xalilova N (2007) Psixologiya fanlarini o'qitish metodikasi. T., “Aloqachi”, 176.

2. Ibodullaev Z (2008) Tibbiyot psixologiyasi: Tibbiyot oily o'quv yurtlari talabalari uchun darslik. O'zR oily va o'rta maxsus ta'lim vazirligi. T.: "IQTISOD-MOLIYA", 380.

3. Akbarova SN, Azimova GA (2014) Psikhologicheskaya dermatoglifika bol'nykh narkomaniey. Molodoy uchenyy. No. 6 (65), pp. 787-789.

4. Akbarova SN (2014) Dermatoglificheskiy analiz psikhologicheskikh yavleniy. Vestnik Tadzhikskogo Tekhnicheskogo universiteta. No. 1(25), pp. 142-144.

5. Antropov YA (2013) Diagnostika psikhicheskikh bolezney: rukovodstvo. Moscow: "GEOTAR-Media", 264.

6. Zaychenko AA (2009) Biometricheskie pokazateli konstitutsional'nykh riskov razvitiya paranoidnoy shizofrenii u muzhchin. Saratovskiy nauchno-meditsinskiy zhurnal. Tom 5. No. 3, pp. 384-389.

7. Shakibaei F, Asadollahi GA, Tabibi A (2011) Dermatoglyphics in patients with schizophrenia. Journal of research in medical sciences: the official journal of Isfahan University of Medical Sciences. T. 16, No. 8, pp. 1055.

8. Velikoretskaya MD (1986) Znachenie dermatoglifiki v klinicheskoy praktiki. Pediatriya. Moscow: "Meditsina", No. 6, pp.3843.

9. Abdullaev BA, Daminov AA (1988) Dermatoglifika pal'tsev u bol'nykh shizofreniey. Aktual'nye voprosy antropogenetiki i toksikogenetiki: sb. nauch. tr., Tashkentskiy gosudarstvennyy meditsinskiy institut. Tashkent, 144.

10. Bramon E, et al. (2005) Dermatoglyphics and schizophrenia: a meta-analysis and investigation of the impact of obstetric complications upon ab ridge count. Schizophrenia research. T. 75, No. 2, pp. 399-404.

11. Weinstein DD, et al. (1999) Minor physical anomalies, dermatoglyphic asymmetries, and cortisol levels in adolescents with schizotypal personality disorder. American Journal of Psychiatry. T. 156, No. 4, pp. 617-623.

12. Mellor CS (1992) Dermatoglyphic evidence of fluctuating asymmetry in schizophrenia. $\mathrm{Br} \mathrm{J}$ Psychiatry 160: 467-472.

13. van Oel CJ, Baaré WF, Hulshoff Pol HE, Haag J, Balazs J, Dingemans A, Kahn RS, Sitskoorn 
MM (2001) Differenting between low and high susceptibility to schizophrenia in twins: the significance of dermatoglyphic indices in relation to other determinants of brain development. Schizophrenia research. No. 52, pp.181-193.

14. Dorodnova AS (2006) Kliniko-sotsial'nye i organizatsionnye aspekty pomoshchi bol'nym shizofreniey i rasstroystvami shizofrenicheskogo spektra s pervymi psikhoticheskimi epizodami. Avtoref. diss. kand. med. nauk., T. 6.

15. Kempinskiy A (1998) Psikhologiya shizofrenii. 'venta, 183.

16. Akbarova SN, Isakhanova NKh (2014) Psikhologiya bol'nykh gipertenziey $\mathrm{s}$ tochki zreniya dermatoglifiki. Molodoy uchenyy, No. 6 (65), pp. 789-791.

17. Badikov KN (2013) K voprosu o psikhologicheskoy dermatoglifiki. Voprosy prava i politiki. No. 6, pp. 351-364.
18. Shamsiev ES (2008) Meditsinskaya psikhologiya. Rukovodstvo, T: 584.

19. Akbarova SN, Matveeva AA (2014) Nasledstvennoe otrazhenie predposylok agressivnosti cheloveka. Novyy universitet. Seriya «Aktual'nye problemy gumanitarnykh i obshchestvennykh nauk» No. 01(34), pp. 103105.

20. Akbarova SN (2007) Shakhs kharakterining konstitutsional-psikhologik zhixatlari: psikhol. fan.nom. dis. Avtoreferat. Toshkent: Nizomiy nomli TDPU, 21.

21. Akbarova SN (2014) Heredity regularity of psychological properties of person. ISJ Theoretical \& Applied Science 2 (10): 132-134. doi:

http://dx.doi.org/10.15863/TAS.2014.02.10.21 